\title{
Testing the Activity of Complement Convertases in Serum/Plasma for Diagnosis of C4NeF-Mediated C3 Glomerulonephritis
}

\author{
Anna M. Blom ${ }^{1} \cdot$ Fernando Corvillo $^{2} \cdot$ Michal Magda $^{1} \cdot$ Grzegorz Stasilojéc $^{6}$. \\ Pilar Nozal $^{2,5}$ • Miguel Ángel Pérez-Valdivia ${ }^{3}$ - Virginia Cabello-Chaves ${ }^{3}$. \\ Santiago Rodríguez de Córdoba ${ }^{4} \cdot$ Margarita López-Trascasa $^{2,5} \cdot$ Marcin Okrój $^{6}$
}

Received: 22 January 2016 / Accepted: 25 April 2016/Published online: 5 May 2016

(C) The Author(s) 2016. This article is published with open access at Springerlink.com

\begin{abstract}
Autoantibodies termed C3-nephritic factor $(\mathrm{C} 3 \mathrm{NeF})$, which stabilize convertases of the alternative complement pathway, often stimulate autoinflammatory diseases. However, knowledge about analogous autoantibodies acting on the classical pathway $(\mathrm{C} 4 \mathrm{NeF})$ is limited to a few reports, which indicate association with kidney dysfunction, systemic lupus erythematous, and infections. $\mathrm{C} 4 \mathrm{NeF}$ may appear independently from $\mathrm{C} 3 \mathrm{NeF}$, but the lack of a routine diagnostic method predisposes $\mathrm{C} 4 \mathrm{NeF}$ for being an underestimated player in autoinflammatory episodes. We tested the activity of classical convertases directly in serum/plasma to screen samples from 13 patients with $\mathrm{C} 3$ glomerulopathies and identified one patient showing significantly prolonged half-life of these enzymes. Observed effect was reproduced by immunoglobulins
\end{abstract}

Electronic supplementary material The online version of this article (doi:10.1007/s10875-016-0290-5) contains supplementary material, which is available to authorized users.

Marcin Okrój

marcin.okroj@gumed.edu.pl

1 Department of Translational Medicine, Lund University, 20502 Malmö, Sweden

2 Immunology Unit, University Hospital La Paz, IdiPAZ, Madrid, Spain

3 Servicio de Nefrología Hospital Universitario Virgen del Rocío, Sevilla, Spain

4 Centro de Investigaciones Biológicas, Consejo Superior de Investigaciones Científicas (CIB-CSIC), Centro de Investigación Médica en Red (CIBERER U738), Madrid, Spain

5 Unit 754, Centre for Biomedical Research on Rare Diseases (CIBERER), Madrid, Spain

6 Department of Medical Biotechnology, Intercollegiate Faculty of Biotechnology UG-MUG, Medical University of Gdańsk, Dębinki 1 street, 80-210 Gdańsk, Poland purified from patient's plasma and additionally confirmed on classical convertase built from purified components. Isolated immunoglobulins protected classical convertases from both spontaneous and inhibitor-driven decay but not from $\mathrm{C} 4 \mathrm{~b}$ proteolysis. The patient had a decreased serum level of $\mathrm{C} 3$, elevated sC5b-9, and normal concentrations of factor $\mathrm{B}$ and $\mathrm{C} 4$. Neither $\mathrm{C} 3 \mathrm{NeF}$ nor other autoantibodies directed against alternative pathway proteins (factor $\mathrm{H}$, factor $\mathrm{B}$, factor I, C3, and properdin) were found. Genetic analysis showed no mutations in C3, CFB, CFH, CFI, MCP, THBD, and DGKE genes. Renal biopsy revealed a membranoproliferative pattern with intense $\mathrm{C} 3$ deposits. Our results underline the importance of $\mathrm{C} 4 \mathrm{NeF}$ as an independent pathogenic factor and a need for the implementation of routine examination of classical convertase activity. Proposed method may enable robust inspection of such atypical cases.

Keywords Complement system · complement convertase · $\mathrm{C} 4 \mathrm{NeF} \cdot \mathrm{C} 3$ glomerulonephritis

$\begin{array}{ll}\text { Abbreviations } \\ \text { C3NeF } & \text { C3 nephritic factor } \\ \text { C4NeF } & \text { C4 nephritic factor } \\ \text { C3G } & \text { C3 glomerulopathy } \\ \text { C3GN } & \text { C3 glomerulonephritis } \\ \text { DDD } & \text { Dense deposit disease } \\ \text { aHUS } & \text { Atypical hemolytic uremic syndrome } \\ \text { Ig } & \text { Immunoglobulin } \\ \text { NHS } & \text { Normal human serum } \\ \text { FB } & \text { Factor B } \\ \text { FD } & \text { Factor D } \\ \text { BSA } & \text { Bovine serum albumin } \\ \text { HRP } & \text { Horseradish peroxidase }\end{array}$


SLE Systemic lupus erythematous

SDS- Polyacrylamide gel electrophoresis with sodium

PAGE dodecyl sulfate

PVDF Polyvinylidene fluoride

\section{Introduction}

Three different routes may drive the complement system, an important constituent of innate immunity: the classical, lectin, and alternative pathways. Whereas the first two pathways are initiated by certain stimuli such as antibodies bound to the cell surface or the presence of pathogen-specific sugar moieties, the alternative pathway is constantly active at a low level and its further propagation depends on the lack of restriction by endogenous complement inhibitors [1]. The alternative or classical/lectin pathway complement convertases are the elements of the cascade, which are particularly controlled by complement inhibitors. Otherwise, convertases produce opsonins, anaphylatoxins, and initiate the formation of the membrane attack complex aimed to lyse target cells [2]. Under physiological conditions, the maximal activity of convertases is reached relatively quickly after pathway initiation (seconds or minutes, depending on complement availability, as shown in [3]) and after this time their activity decreases due to spontaneous and inhibitor-driven decay as well as proteolysis of $\mathrm{C} 3 \mathrm{~b}$ and $\mathrm{C} 4 \mathrm{~b}$ components by factor I [4]. Diverse modes of complement activation determine the risk of autoinflammatory diseases resulting from misguided or uncontrolled complement attack. A loss of regulation of the alternative pathway is sufficient for pathologic events whereas in the case of the classical and lectin pathways, an analogous condition must be accompanied with a pathway-specific stimulus present on self cells. Indeed, mutations in alternative pathway components are well-known etiologic/risk factors for diseases such as $\mathrm{C} 3$ glomerulopathies (C3G) [5] or atypical hemolytic uremic syndrome (aHUS), which manifest already at a very young age [6]. Another condition, which leads to the unrestricted activity of alternative convertases, is the presence of autoantibodies termed $\mathrm{C} 3 \mathrm{NeF}$. C3NeF binds neoepitopes formed upon the assembly of the convertase and stabilizes it, resulting in consumption of $\mathrm{C} 3$ (hypocomplementemia) and amplification of downstream events in the complement cascade. Occurrence of $\mathrm{C} 3 \mathrm{NeF}$ is reported in almost all patients with dense deposit disease and in half of the patients with $\mathrm{C} 3 \mathrm{GN}$ [7]. Interestingly, this autoantibody was also found in an individual showing no disease symptoms [8] and its presence in some $\mathrm{C} 3 \mathrm{GN}$ patients did not cause hypocomplementemia [9], but, on the other hand, the same study reported $\mathrm{C} 3 \mathrm{NeF}$-positive $\mathrm{C} 3 \mathrm{GN}$ in the absence of other known disease-causing agents [9]. In contrast to the deregulation of alternative pathway convertases by either mutations in pivotal pathway components or autoantibodies, similar phenomena for the classical pathway convertases are poorly described, with not a single report about a gain-offunction mutation and only a few reports about $\mathrm{C} 4 \mathrm{NeF}$ (analogous to $\mathrm{C} 3 \mathrm{NeF}$ ). Incidence of $\mathrm{C} 4 \mathrm{NeF}$ was briefly reviewed in [10] and reported in postinfectious glomerulonephritis [11, 12], membranoproliferative glomerulonephritis [13], systemic lupus erythematous [14], and recently in a patient with sepsis caused by Neisseria meningitidis [15]. There are two reports on $\mathrm{C} 4 \mathrm{NeF}$ occurrence in large cohorts with renal diseases, which show $\mathrm{C} 4 \mathrm{NeF}$ in 19 out of 100 patients [13] and 19 out of 197 patients [16], respectively. Interestingly, the percentage of patients double-positive for $\mathrm{C} 3 \mathrm{NeF}$ and $\mathrm{C} 4 \mathrm{NeF}$ was 52 [13] and $10 \%$ [16] depending on cohort, showing that these two kinds of activities may appear independently of each other. Also, there are reports showing that $\mathrm{C} 4 \mathrm{NeF}$ may stabilize not only $\mathrm{C} 3$ classical convertase but also $\mathrm{C} 5$ classical convertase $[15,17]$. There is no routine diagnostic procedure for $\mathrm{C} 4 \mathrm{NeF}$ determination. Available experimental methods are based on multistep hemolytic assays performed on sheep erythrocytes coated with purified components of classical convertases (EAC142 or EAC1423) [13, 15] or precipitation of stabilized fluid-phase $\mathrm{C} 4 \mathrm{~b} 2 \mathrm{a}$ complexes followed by detection by sandwich ELISA [18]. An obvious limitation of detection systems based on purified complement components is elimination of interactions with other components from autologous serum, which are normally present under physiological conditions and may influence convertase formation and stability. On the other hand, detection of stabilized, fluid-phase classical convertase precipitated from patient serum does not give any information about enzymatic activity. We have designed a new method for assessment of convertase activity directly in patient's serum or plasma, which makes use of C5 blockers: OmCI or eculizumab [19]. Thereafter, we showed that our approach enables proper detection of clinical samples with altered function of alternative convertases caused by either autoantibodies $(\mathrm{C} 3 \mathrm{NeF}$, anti-factor $\mathrm{H})$ or mutations in complement proteins (C3, factor B) [19]. Herein, we report the usage of this method for screening for abnormally prolonged activity of classical convertases and, by doing so, identification of $\mathrm{C} 4 \mathrm{NeF}$ activity in a patient with $\mathrm{C} 3$ glomerulonephritis of previously unknown etiology. Further analysis revealed that the specific activity responsible for the phenotype was conferred in the Ig fraction isolated from plasma.

\section{Materials and Methods}

\section{Reagents, Sera and Patient Material}

Normal human serum (NHS) was prepared from blood of healthy volunteers after written informed consent had been obtained and according to the permit by the ethics committee in Lund (permit number 2013/846). Blood was collected and 
kept at room temperature for 30 min to coagulate, then on ice for another $60 \mathrm{~min}$ followed by centrifugation for $7 \mathrm{~min}$ at $700 \times g$. The serum fraction was collected, centrifuged again to remove residual erythrocytes, aliquoted, and stored at $-80{ }^{\circ} \mathrm{C}$ until use. Thirteen patients with biopsy-proven $\mathrm{C} 3$ glomerulopathy ( 3 with dense deposit disease and 10 with C3 glomerulonephritis) diagnosed between 1970 and 2015 were selected based on the availability of sera and/or plasma samples to complete all assays, as well as histopathologic data (light microscopy, immunofluorescence, and electron microscopy) to review the pathologic diagnosis. Serum and EDTAplasma samples were obtained under standard conditions with informed consent and with the approval of Hospital Universitario La Paz; blood was collected into plain tubes, allowed to clot at room temperature, and centrifuged for 10 min at $4{ }^{\circ} \mathrm{C}$. After that, serum and plasma were collected, aliquoted, and kept frozen at $-80{ }^{\circ} \mathrm{C}$ until use. List of the patients with indicated diagnoses and complement-related parameters is given in Table 1. Purified human $\mathrm{C} 2, \mathrm{C} 3, \mathrm{C} 4, \mathrm{C} 4 \mathrm{~b}$, FB, FD, properdin, FI, and FH were purchased from Comp Tech. OmCI, a recombinant inhibitor of C5 cleavage, was expressed and purified as described in [19]. Guinea pig serum was purchased from Harlan Laboratories. Human sera depleted from $\mathrm{C} 3$ and/or C5 as well as mouse anti- C4d antibody (A253) were purchased from Quidel. Soluble CD55 (DAF) was produced recombinantly in eukaryotic system as described [20]. Factor I (FI) [21] and C4b-binding protein (C4BP) [22] used in $\mathrm{C} 4 \mathrm{~b}$ degradation assay were purified from human plasma. Monoclonal antibody MK104 against C4BP was homemade and purified using protein A affinity chromatography as described [23].

\section{Genotyping and Mutation Screening}

Genomic DNA was extracted from peripheral blood using standard procedures. Exons of the $C F H, M C P, C F I, C 3$, $C F B, T H B D$, and $D G K E$ genes were amplified from genomic DNA using primers derived from the intronic sequences as described [24-26]. Automatic sequencing was performed in an ABI3730 sequencer using a dye terminator cycle sequencing kit (Applied Biosystems). The analysis of the $D_{\text {CFHR3- }}$ CFHRI polymorphism and genomic rearrangements in the CFH-CFHRs region were assessed by multiplex ligationdependent probe amplification (MLPA) with the P236 A1 ARMD mix 1 (MRC-Holland, Amsterdam, Netherlands).

\section{Properdin, C3, C4, FB, C5, and sC5b-9 Quantification}

Properdin levels were measured by ELISA as described in [27]. Serum levels of $C 3$ and $C 4$ were measured by nephelometry (Siemens Healthcare, Marburg, Germany). Serum FB levels were determined by ELISA using $100 \mathrm{ng} /$ well of protein $\mathrm{G}$ (GE Healthcare) purified polyclonal goat IgG anti-

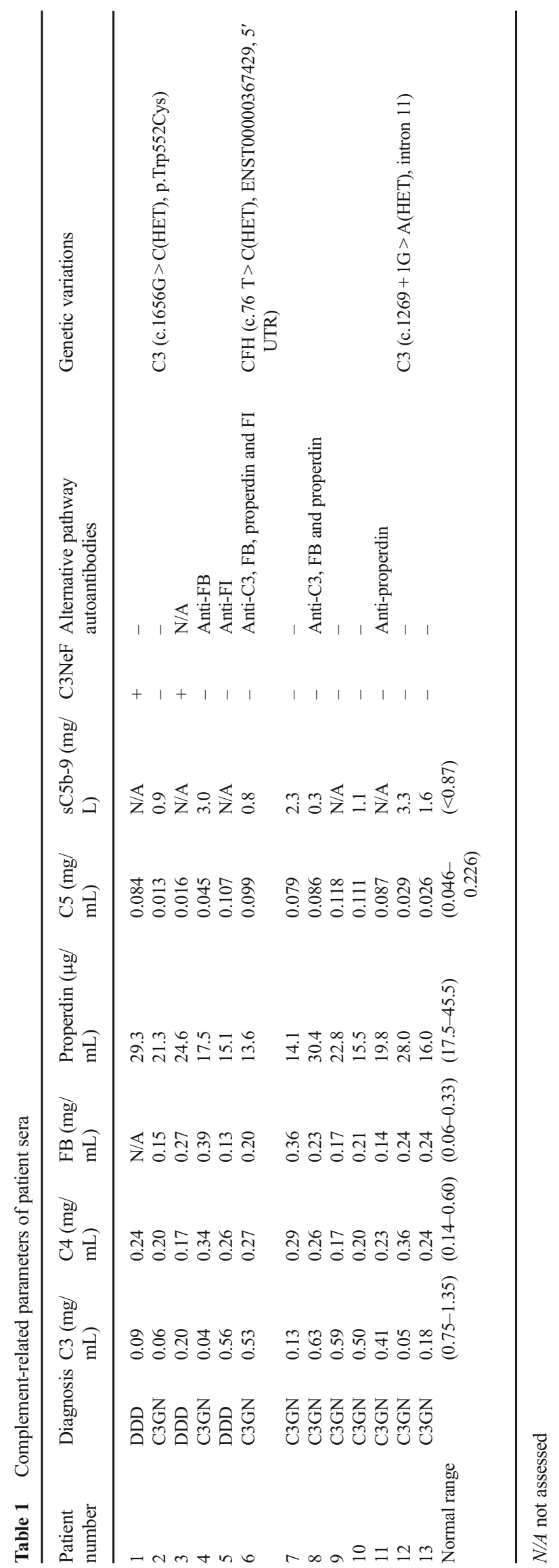


human FB antibody (Calbiochem, \#341272) as capture antibody and a monoclonal mouse anti-human $\mathrm{Bb}$ (A227, Quidel, San Diego, CA) as the detection antibody. C5 serum levels were determined following an ELISA described in [28]. Circulating sC5b-9 was analyzed using a commercially available assay (A029, Quidel).

\section{C3NeF Detection by ELISA}

$\mathrm{C} 3 \mathrm{NeF}$ detection in serum samples was performed as previously described [29] with several modifications. Briefly, two ELISA assays were performed: COSP (to measure the stabilizing-capacity of serum $\mathrm{C} 3 \mathrm{NeF}$ ) and $\mathrm{COIgG}$ (to detect the binding of $\mathrm{C} 3 \mathrm{NeF}$ to the AP C3 convertase). In both assays, ELISA plates (Medisorp, Nunc) were coated with $\mathrm{C} 3 \mathrm{~b}$ $\left(1 \mu \mathrm{g} / \mathrm{ml}\right.$ in PBS, overnight, $\left.4{ }^{\circ} \mathrm{C}\right)$. Convertase was formed by adding $50 \mu \mathrm{l}$ test serum (1/50 in assay buffer), immediately followed by $50 \mu$ of a mixture comprising FB $(1 \mu \mathrm{g} / \mathrm{ml})$ and FD $(0.2 \mu \mathrm{g} / \mathrm{ml})$ with properdin $(0.5 \mu \mathrm{g} / \mathrm{ml})$ in assay buffer. For COSP, a 1/500 dilution of a monoclonal anti-human $\mathrm{Bb}$ fragment (Quidel, \#A227) was used to detect the presence of residual $\mathrm{Bb}$ fragments on the stabilized $\mathrm{C} 3 \mathrm{bBbP}$ complex. $\mathrm{A}$ peroxidase-conjugated goat anti-mouse $\operatorname{IgG}(\mathrm{H}+\mathrm{L})$ (Invitrogen) diluted 1:1000 was used as secondary antibody, and the reaction was developed with OPD. The COIgG assay was performed as described in [29] except that the assay buffer contained $1 \mathrm{mM}$ of $\mathrm{MgCl}_{2}$ instead of $\mathrm{NiSO}_{4}$ in order to reduce background.

\section{Antibody Binding to Immobilized C3, FB, FI, FH, and Properdin}

ELISA plates were coated with $100 \mathrm{ng} /$ well of purified C3, FB, FI, FH, or properdin. Plates were blocked with PBS-BSA $3 \%$ in case of FB and properdin, and with PBS-BSA $0.1 \%$ in FI and C3. Serum samples were diluted in PBS-BSA $0.1 \%$, and binding of autoantibodies was detected with polyclonal anti-human IgG-HRP conjugated antibody (Jackson Immunoresearch) in ABTS substrate, as described in [30]. Factor $\mathrm{H}$ autoantibodies were analyzed as previously described in [31].

\section{Purification of Whole Ig Fraction}

Whole Ig fraction was purified from $1 \mathrm{ml}$ of EDTA-plasma of patient seven and $1 \mathrm{ml}$ of normal human serum pooled from 13 healthy volunteers, by affinity chromatography on $5 \mathrm{ml}$ protein A and protein G Sepharose Hi-Trap columns (GE Healthcare). Samples were loaded, the unbound fraction was washed with PBS buffer and then Ig eluted with $0.1 \mathrm{M}$ glycine- $\mathrm{HCl}$ buffer $\mathrm{pH} 2.5$. Fractions containing proteins were immediately neutralized with $1 / 10$ volume of $1 \mathrm{M}$ Tris- $\mathrm{HCl}$
$\mathrm{pH}$ 8.0, dialyzed against PBS, and concentrated using $10 \mathrm{kDa}$ molecular weight cut-off value device (Vivaspin).

\section{Functional Assays for Activity of Classical Convertases}

Activity of classical complement convertases was tested either in full serum/plasma or in a setting with whole Ig fraction purified from patients' blood, as described in [19] and [3], respectively. Additional analysis testing the stability of convertases built up from purified components was performed on sheep erythrocytes (Hatunalab AB or BioMaxima) sensitized with anti-sheep erythrocyte antibody Amboceptor (Behring). Erythrocytes were prepared as described [3] and then incubated with $2.5 \mu \mathrm{g} / \mathrm{ml}$ of $\mathrm{C} 1$ and $\mathrm{C} 4$ for $10 \mathrm{~min}$ at $30{ }^{\circ} \mathrm{C}$ in DGVB veronal buffer. Afterwards, $2.5 \mu \mathrm{g} / \mathrm{ml}$ of $\mathrm{C} 2$ was added with various dilutions of whole Ig fraction isolated from patient seven or normal human serum. Incubation was performed for up to $90 \mathrm{~min}$, and reaction was stopped at chosen time points. Erythrocytes were washed with ice-cold $40 \mathrm{mM}$ EDTA-GVB buffer and centrifuged for $1 \mathrm{~min}$ at $1000 \times \mathrm{g}$. Pellets were resuspended in $50 \mu \mathrm{l}$ of fresh $40 \mathrm{mM}$ EDTA-GVB containing guinea pig serum diluted 1:40 and overlaid with additional $50 \mu \mathrm{l}$ of DGVB. After $20 \mathrm{~min}$ of incubation at $37{ }^{\circ} \mathrm{C}$, cells were centrifuged. Supernatant was collected and placed in a flat-bottom plate, and absorbance at $405 \mathrm{~nm}$ was measured with a microplate reader.

\section{Determination of C4d Content}

C4d measurement aimed to determine the rate of $\mathrm{C} 4 \mathrm{~b}$ inactivation by FI-mediated cleavage was performed by sandwich ELISA assay using anti-neoepitope $\mathrm{C} 4 \mathrm{~d}$ antibodies raised inhouse, as described in [32]. Samples containing $5 \mu \mathrm{g} / \mathrm{ml} \mathrm{C4b}$ (Comp Tech) and $10 \mu \mathrm{g} / \mathrm{ml}$ of C4BP and FI and alternatively control or patient's whole Ig fraction or $500 \mu \mathrm{g} / \mathrm{ml}$ of rabbitanti C4c antibody (Dako, \#Q0369) were incubated for $1 \mathrm{~h}$ and then loaded onto ELISA plate.

\section{Visualization of C4b Cleavage Pattern}

Thirty microgram per milliliter of $\mathrm{C} 4 \mathrm{~b}$ (Comp Tech) and $100 \mu \mathrm{g} / \mathrm{ml}$ of C4BP were mixed and optionally supplied with $10 \mu \mathrm{g} / \mathrm{ml}$ of FI and $500 \mu \mathrm{g} / \mathrm{ml}$ of rabbit-anti C4c antibody. Mixture was incubated overnight at $37{ }^{\circ} \mathrm{C}$, and then $3 \mathrm{x}$ Laemmli buffer was added and after boiling for 5 min samples were separated by $10 \%$ SDS-PAGE. After electrophoresis gel was blotted onto PVDF membrane and signal from C4 fragments was developed with mixture of 1:1000 mouse anti-C4d (clone LP69, Abcam) and 1:1000 of goat antiC4 (Comp Tech, \#A205), followed by mixture of goat anti-rabbit and anti-mouse HRP-conjugated Abs (Dako, 
\#P0448 and \#P0447). Western blot was visualized with $\mathrm{DAB}$, as described in [33].

\section{Results}

\section{Screening of Serum/Plasma Samples for Prolonged Activity of Classical Complement Convertases}

The plasma/serum samples of 13 patients with confirmed C3 glomerulopathies (listed in Table 1) were included in a screening assay testing the activity of classical convertases over time (Fig. 1). Since the patients presented with different degrees of hypocomplementemia, all samples were diluted to $1 \%$ final concentration and then mixed with an equal amount of normal human serum (NHS). This step enabled normalization of the readout but the addition of an extra $1 \%$ of NHS did not affect convertase activity curves, as evidenced by the lack of differences between 1 and $2 \%$ NHS samples (Fig. 1). However, it allowed the detection of factors present in individual serum/ plasma samples which caused prolongation of classical convertase activity. In the case of sample 7, convertase activity was significantly elevated from the time point of $5 \mathrm{~min}$ ( $p<0.01$ according to two-way ANOVA, comparing to $1 \%$ NHS) and continued to time points of 10 and $20 \mathrm{~min}$ $(p<0.001)$. The activity of other clinical samples did not differ significantly from NHS controls (Supplementary Fig. 1).

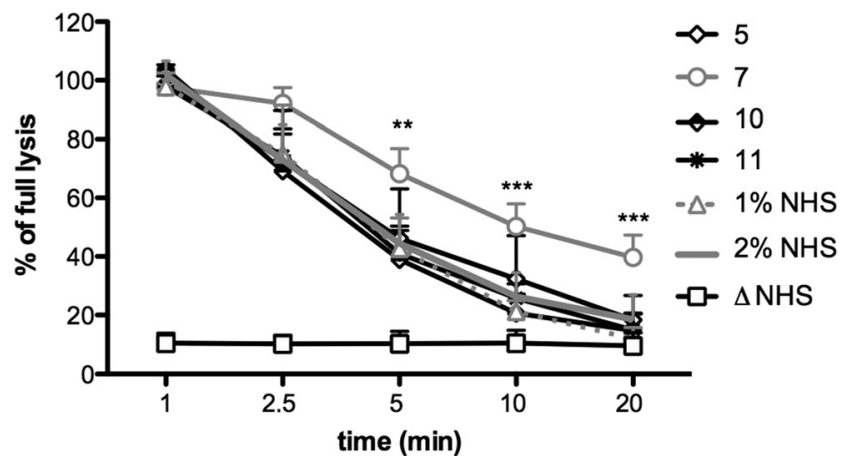

Fig. 1 Screening of clinical serum and plasma samples for prolonged activity of classical convertases. Thirteen samples collected from the patients with $\mathrm{C} 3$ glomerulopathies were diluted to final concentration of $1 \%$, mixed with equal volume of NHS and inhibitor of C5 cleavage was added. Samples were incubated with sensitized sheep erythrocytes for indicated time period and then washed and incubated with guinea pig serum diluted in $40 \mathrm{mM}$ EDTA-GVB buffer, which disabled de novo convertase formation but allowed development of lytic sites only from pre-existing convertases. Percentage of lysis measured at $405 \mathrm{~nm}$ was referred to the equal amount of sensitized erythrocytes lysed with equal volume of water. Data were collected from three independent experiments, statistical significance was assessed by two-way ANOVA at $* * p<0.01$ and $* * * p<0.001$, respectively. Only four clinical samples including \#7 were shown for better clarity of the graph but none of the clinical samples but \#7 showed statistically significant differences when compared to NHS controls. Graph showing all 13 patients versus healthy controls (normal human serum) is presented in Supplementary Fig. 1
Stabilization of the Classical C3/C5 Convertase Activity Is Supported by the Ig Fraction Isolated from the Patient's Plasma

We investigated whether the effect on classical convertase exerted by plasma from patient seven could be reproduced by addition of the Ig fraction only to $1 \%$ NHS. Total Ig was purified from $1 \mathrm{ml}$ of the patient's plasma by protein $\mathrm{A} / \mathrm{G}$ affinity chromatography. The obtained preparation was concentrated to the initial plasma volume and used in an experiment similar to that presented in Fig. 1. Results showed no significant differences between NHS supplemented either with $1 \%$ patient's serum or an equal volume of purified Ig fraction (Supplementary Fig. 2). To confirm whether the prolonged stability of the classical complement convertase in the plasma of patient seven is attributed to $\mathrm{C} 4 \mathrm{NeF}$ activity, we investigated whether purified antibodies from patient seven stabilize both $\mathrm{C} 3$ and $\mathrm{C} 5$ classical convertases. To answer this question, we applied another assay described in [3], which operates in C3- or C5-depleted serum. These sera support the formation of $\mathrm{C} 3$ and $\mathrm{C} 5$ classical convertases, respectively, on $\mathrm{Ab}$-sensitized sheep erythrocytes. Addition of Ig purified from patient seven resulted in significantly prolonged activity of both classical convertases when compared to control Ig purified from NHS (Fig. 2).

\section{C4NeF from Patient Seven Prevents Both Spontaneous and Inhibitor-Driven Convertase Decay but Not Factor I-Mediated Proteolysis of C4b}

Further experiments aimed to identify the mechanism, by which $\mathrm{C} 4 \mathrm{NeF}$ isolated from patient seven stabilizes classical convertases. First, we checked whether putative binding of autoantibodies to classical convertases protects them from spontaneous decay. Convertases were built up by deposition of purified $\mathrm{C} 1$ and $\mathrm{C} 4$ onto the surface of sensitized sheep erythrocytes followed by the addition of purified $\mathrm{C} 2$ together with Ig isolated from the patient or from NHS. Additional controls were aimed to test convertase decay, when either no Ig or a soluble version of complement inhibitor CD55 (CD55$\mathrm{Fc}$ ) were added. Erythrocytes incubated without $\mathrm{C} 2$ served as negative control. The addition of Ig isolated from NHS did not affect the convertase activity profile in contrast to the addition of Ig isolated from patient seven, which stabilized convertase activity (Fig. 3a). Addition of CD55-Fc resulted in diminished convertase activity at the first time point tested and a subsequent, rapid drop of activity down to the level of the negative control, as expected. Thereafter, we tested whether $\mathrm{C} 4 \mathrm{NeF}$ from patient seven is capable of counteracting inhibitors which accelerate convertase decay, using the inhibitor CD55 as a model. Addition of $\mathrm{C} 4 \mathrm{NeF}$ could not rescue the initial drop of convertase activity measured at the first time point, but in contrast to control Ig it efficiently prevented the accelerated 


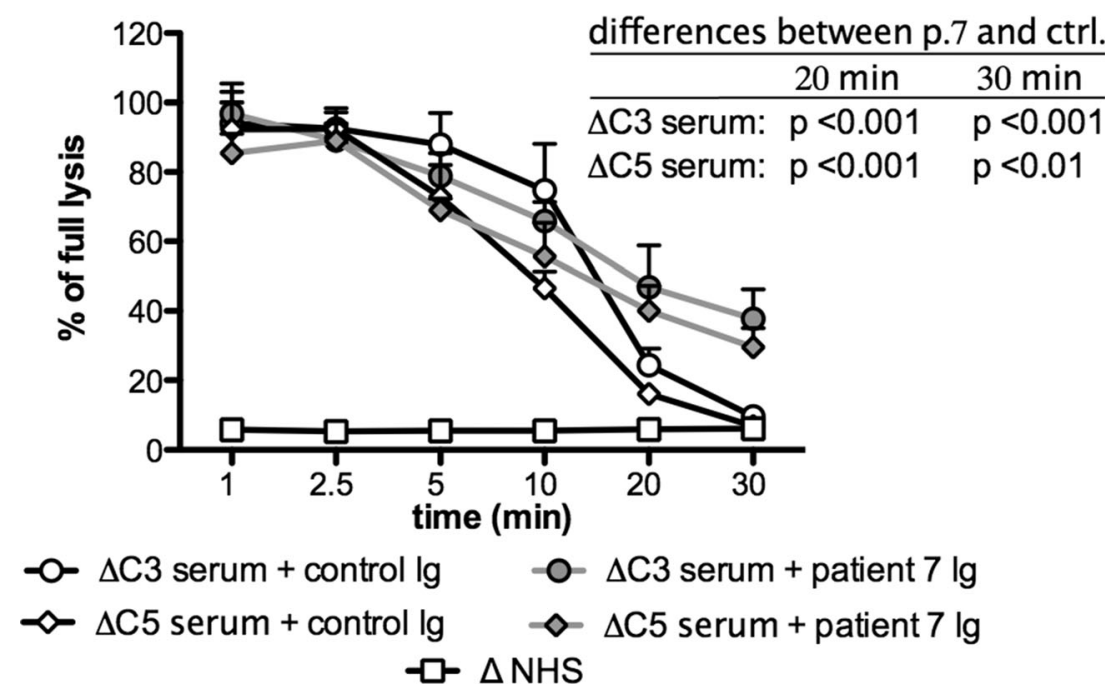

Fig. 2 Influence of patient's and control Ig on stability of C3 and C5 classical convertases. In order to assess the influence of total Ig fraction purified from patient seven plasma on classical C3 and C5 convertase, Ig preparations were mixed with $1 \% \mathrm{C} 3$-depleted or C5-depleted serum, respectively, and incubated with sensitized sheep erythrocytes for an indicated period of time. Samples were wzashed and incubated with guinea pig serum diluted in $40 \mathrm{mM}$ EDTA-GVB buffer, which disabled

drop in activity at further time points (Fig. 3b). Next, we checked whether $\mathrm{C} 4 \mathrm{NeF}$ from patient seven also protected convertases from the FI-mediated cleavage of $\mathrm{C} 4 \mathrm{~b}$. For example, antibodies targeting C4 may hinder binding sites for FI and/or its cofactors, and by doing so, disable $\mathrm{C} 4 \mathrm{~b}$ cleavage, as we showed in Fig. 3c for anti-C4c antibodies. Our preliminary experiment, in which we tested patient's and control Igs in the same setting, did not show differences in $\mathrm{C} 4 \mathrm{~b}$ cleavage (not shown). However, reliable visualization of $\mathrm{C} 4 \mathrm{NeF}$ influence on $\mathrm{C} 4 \mathrm{~b}$ cleavage with this method would demand substantial quantities of isolated $\mathrm{C} 4 \mathrm{NeF}$, which we could not supply. Therefore, we chose another technique based on the quantification of the C4d cleavage product by a highly sensitive sandwich ELISA [32], which allowed minimizing the amount of required $\mathrm{C} 4 \mathrm{~b}$ and so enabled the testing of a fair molar excess of antibodies over C4b. Surprisingly, there was a trend toward a more pronounced generation of $\mathrm{C} 4 \mathrm{~d}$ when the patient's Ig were present but these differences did not reach statistical significance at any of the Ig concentrations tested (Fig. 3d). Nonetheless, based on these results, we conclude that the $\mathrm{C} 4 \mathrm{NeF}$ activity of Ig isolated from patient seven could not be attributed to an interference with proteolytic inactivation of $\mathrm{C} 4 \mathrm{~b}$. Using analogous method and function-blocking antibodies against FI and C4BP, we tried to assess the importance of convertase decay-acceleration versus FI-mediated proteolysis of $\mathrm{C} 4 \mathrm{~b}$ for overall convertase activity. Unfortunately, addition of purified $\mathrm{IgG}$ fraction isolated from the patients diminished trustful range of readout and prevented from reliable conclusions (not shown). Nonetheless, in previous publication, we de novo convertase formation but allowed development of lytic sites only from pre-existing convertases. Percentage of lysis measured at $405 \mathrm{~nm}$ was referred to the equal amount of sensitized erythrocytes lysed with equal volume of water. Ig preparation from NHS was used as a negative control. Data were collected from three independent experiments; statistical significance was assessed by two-way ANOVA

showed that blocking of FI function does not affect stability of classical convertases as much as blocking of C4BP [3] and extrapolation of these findings seems to be applicable in the current case.

\section{Clinical Manifestation of Disease in Patient Seven}

In order to analyze the case of patient seven, the only individual whose sample was yielding positive result in our $\mathrm{C} 4 \mathrm{NeF}$ screening assay, we investigated related clinical data. He was a 55-year-old man referred to a hospital for a nephrotic syndrome study, on the basis of a casual finding of high proteinuria in a periodic analytical control. There was no familial history of renal disease, but he and his father and brothers are diagnosed with dyslipidemia and systemic arterial hypertension. At the time of the study, the patient presented normal blood cell counts, decreased total serum protein levels ( $48 \mathrm{mg} /$ $\mathrm{mL})$, as well as low serum albumin $(2.8 \mathrm{mg} / \mathrm{mL})$. $\operatorname{IgG}$ count was also low (4.23 mg/mL, normal range 7.25-19), but $\operatorname{IgA}$ and IgM were normal $(1.53 \mathrm{mg} / \mathrm{mL}$, normal range $0.5-3.4$ and $0.83 \mathrm{mg} / \mathrm{mL}$, normal range $0.45-2.8$, respectively). Serum creatinine and urea were at the upper limit of normal range $(12$ and $400 \mathrm{mg} / \mathrm{L})$. Hematuria and proteinuria $(2 \mathrm{~g} / \mathrm{L})$ were found, reaching up to a protein loss of $16 \mathrm{~g}$ in 24-h urine analysis. Complement $\mathrm{C} 3$ serum levels were decreased, but $\mathrm{C} 4$ and $\mathrm{Clq}$ were within their normal ranges and factor $\mathrm{B}(\mathrm{FB})$ was even higher than normal range. A test for anti-nuclear autoantibodies was negative.

At this time, renal biopsy was performed. Of the 36 glomeruli obtained in the biopsy, three were totally sclerosed. 
A
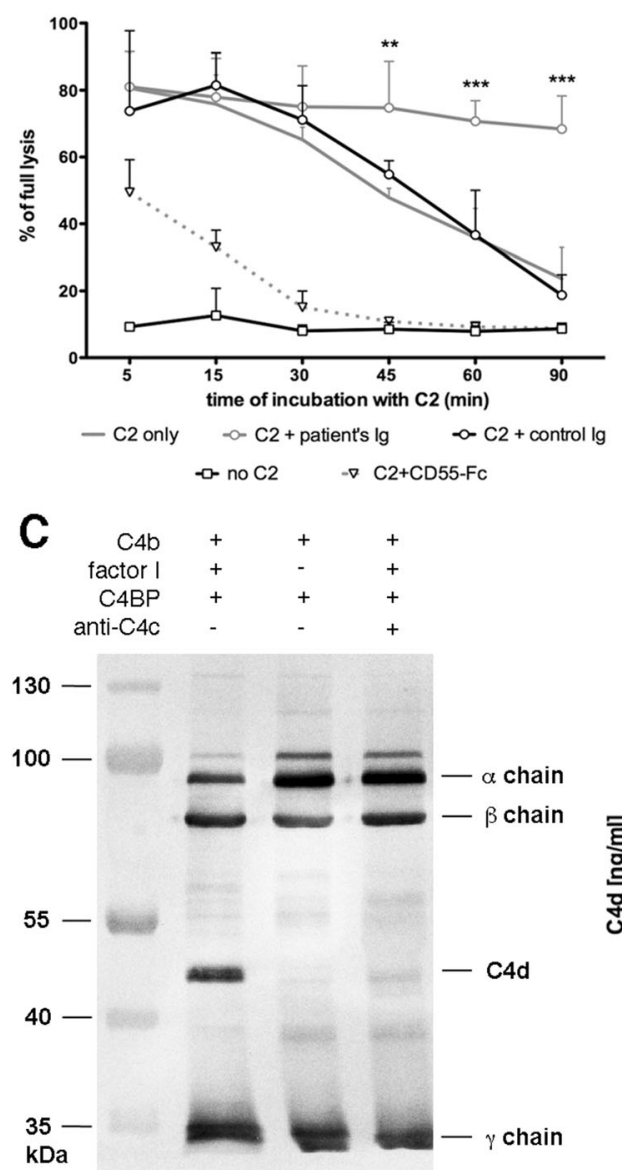

Fig. 3 Mechanism of convertase stabilization by $\mathrm{C} 4 \mathrm{NeF}$ isolated from patient seven. a Spontaneous decay of classical C3 convertase assembled from purified components. Sensitized erythrocytes were coated with $\mathrm{C} 1$ and $\mathrm{C} 4$. Addition of $\mathrm{C} 2$ initiated the process of convertase formation. Convertase activity was assessed at indicated time points in the same manner, as described in Figs. 1 and 2. b The same experiment as in a but with CD55-Fc added together with $\mathrm{C} 2$. $\mathbf{c}$ Representative blot of the $\mathrm{C} 4 \mathrm{~b}$ degradation pattern ( $\mathrm{C} 4 \mathrm{~b}$, factor $\mathrm{I}$, and $\mathrm{C} 4 \mathrm{BP}$ present) and comparison to negative control with no factor I added and sample, in

Extracapillary proliferation was absent and sporadic leukocytic infiltrations were observed. Biopsy showed diffuse increased capillary walls, with split basal membrane and irregular subendothelial deposits. On direct immunofluorescence, intense clumpy $\mathrm{C} 3$ deposits on glomerular capillaries and mesangium were observed. IgG deposits showed a similar pattern but with lower intensity. Capillary and mesangial $\mathrm{IgM}, \mathrm{C} 1 \mathrm{q}$, and $\mathrm{C} 4 \mathrm{~d}$ deposits were also evidenced, and kappa and lambda chains to a lesser extent. A complement relatedglomerular disease was suspected, because of the membranoproliferative pattern with the intense $\mathrm{C} 3$ deposits observed in the biopsy and the persistently decreased $\mathrm{C} 3$ serum levels. Three months after diagnosis, renal function was progressively worsening, with serum creatinine of $13.7 \mathrm{mg} / \mathrm{L}$ and persistent nephritic syndrome; the patient was referred to perform additional, detailed complement studies. The
B

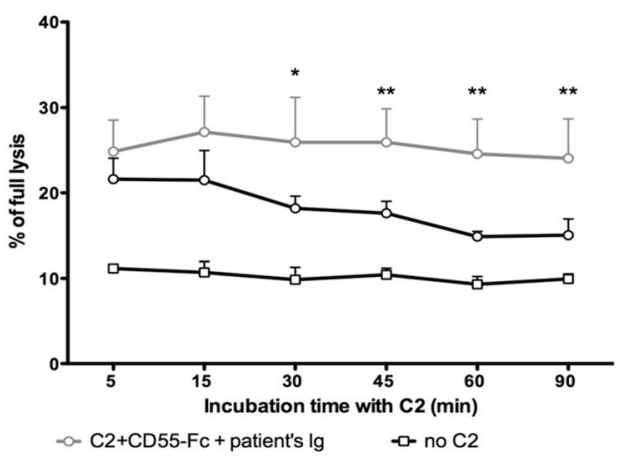

- $\mathrm{C} 2+\mathrm{CD} 55-\mathrm{Fc}+$ control lg

D

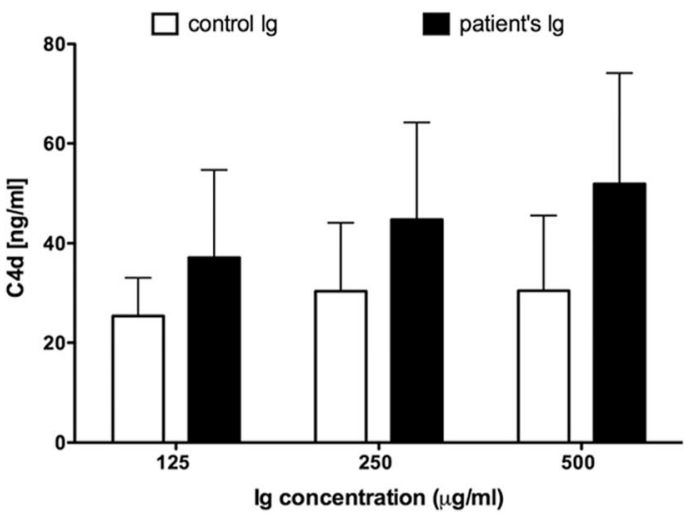

which C4b cleavage was inhibited by excessive anti-C4c antibody. $\mathbf{d}$ Quantification of $\mathrm{C} 4 \mathrm{~d}$ produced upon $\mathrm{C} 4 \mathrm{~b}$ degradation in the presence of Igs isolated from patient seven or from NHS. When anti-C4c antibodies were tested in the same experiments, $\mathrm{C} 4 \mathrm{~d}$ readout was below the lower level of detection and therefore is not shown. All graphs show data collected from at least 3 independent experiments and statistical significance was assessed with two-way ANOVA assay at $* p<0.05$, $* * p<0.0,1$ and $* * * p<0.001$

decreased levels of circulating complement $\mathrm{C} 3$ and properdin suggested alternative pathway activation, but FB was not diminished. The patient had a high C5 convertase activity, which was reflected by a $\mathrm{C} 5$ concentration within lower levels of normal range and elevated sC5b-9. The patient was screened for the presence of $\mathrm{C} 3 \mathrm{NeF}$ and other autoantibodies directed to alternative pathway proteins (FH, FB, FI, C3, and properdin), and all resulted negative. In the genetic analysis, no mutations were identified in $C 3, C F B, C F H, C F I, M C P$, $T H B D$, and $D G K E$ genes.

\section{Technical Performance of the Assay}

We propose that our assay may be used as an efficient screening method for presence of factors interfering with activity of classical convertases. In order to evaluate the reproducibility 
of the assay, we assessed intra- and inter-assay coefficient of variation $(\mathrm{CV})$. Such analyses were performed for $1 \%$ normal human serum sample expected to reflect normal profile of classical convertases activity over the time. In order to additionally validate the method and to visualize the effect of negative and positive controls, we also analyzed $1 \%$ serum supplemented with $300 \mathrm{nM}$ of soluble CD55-Fc (modeling the influence of convertase inhibitors and resulting in diminished convertase activity) and serum supplemented with $300 \mathrm{nM}$ of MK104 (monoclonal antibody, which blocks function of C4BP, the main fluid-phase inhibitor of classical convertases [34]) resembling the effect of $\mathrm{C} 4 \mathrm{NeF}$. Intra-assay $\mathrm{CV}$ was performed with eight repetitions per experiment, which represented whole column of standard, 96-well microplate whereas inter-assay CV was calculated from three independent experiments (Fig. 4). Intra-assay $\mathrm{CV}$ values did not exceed $8 \%$ for any of time points. Average inter-assay CV values obtained for control and MK104 samples were 8.8 and $12.6 \%$, respectively. However, higher CV values were obtained only for samples representing low readout. This was evident for CD55Fc samples, which generally achieved very low readouts but variability at such close-to-background level within separate experiments resulted in substantial CV values. Nonetheless, statistical significance for difference between $\mathrm{CD} 55-\mathrm{Fc}$ and control samples was achieved and we assume that our method offers a good chance to distinguish samples with hyperactive classical convertases. Importantly, experiments on intra- and inter-assay CV were performed on separate batches of erythrocytes from two different vendors and obtaining of similar patterns of convertase activity additionally ensure the reproducibility of the method.

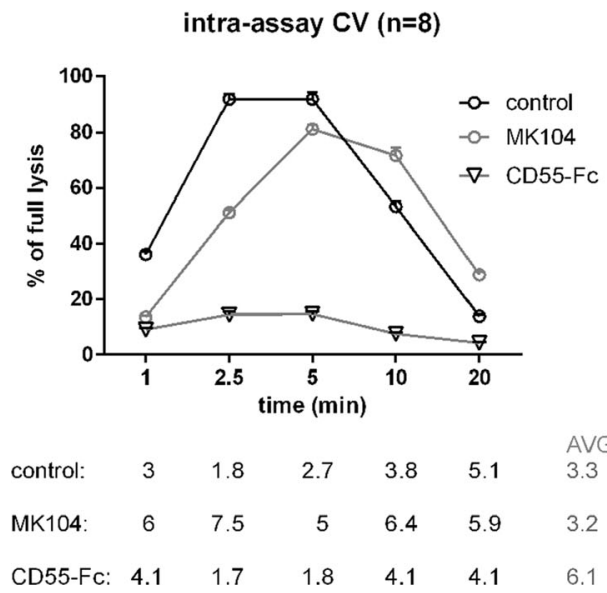

Fig. 4 Reproducibility of the assay testing the activity of classical complement convertases. Intra- (left panel) and inter- (right panel) assay coefficient of variation were assessed for control sample (1\% NHS), positive control sample (1\% NHS supplemented with $300 \mathrm{nM}$ MK104), and negative control sample (1\% NHS supplemented with

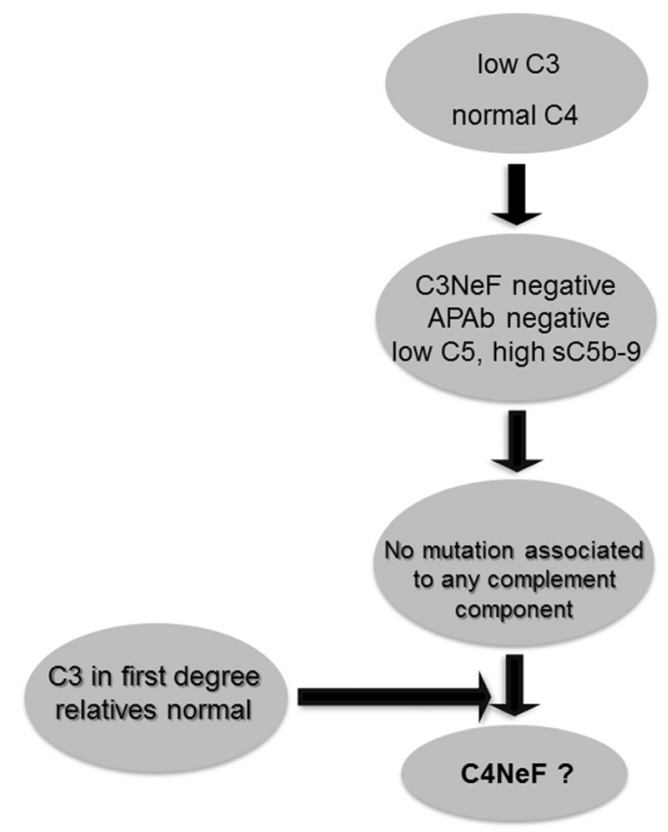

Fig. 5 Algorithm for selection of patients with hyperactive classical convertases. APAB antibodies against alternative pathway components

\section{Discussion}

Convertases are central enzymatic complexes in the complement system, as they catalyze $\mathrm{C} 3$ and $\mathrm{C} 5$ activation, produce anaphylatoxins, and initiate the terminal lytic pathway. Therefore, it is not surprising that the majority of endogenous inhibitors including factor $\mathrm{H}$, factor I, C4BP, CR1, CD46, and CD55 control convertase activity $[35,36]$ and that pushing the balance between convertase activation and inhibition by either mutations or autoantibodies results in autoinflammatory events. Certain complement inhibitors like factor $\mathrm{H}$ possess

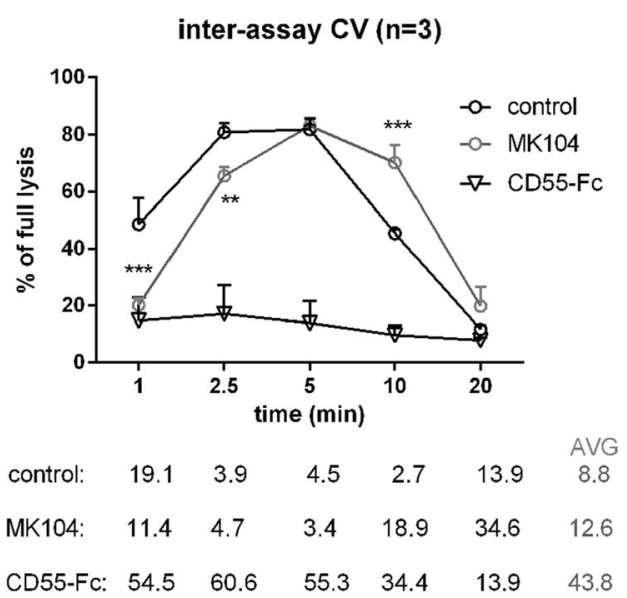

$300 \mathrm{nM}$ CD55-Fc). CV values for each time point are given in percent under the graphs, and average values are indicated with gray font. Statistical significance was assessed with two-way ANOVA assay at $* * p<0.01$ and $* * * p<0.001$ 
multiple polymorphic variants but, paradoxically, different mutations causing redundant phenotypes in terms of complement regulatory function do not predispose to the same disease [37]. This is partially explained by interactions with carbohydrates, which form distinct patterns depending on their locations, e.g., the brain, eye, or kidney [38]. However, the matter seems to be more complex and one of the acknowledged theories assumes the need of multiple hits by gain-offunction mutations in complement activators, loss-of-function mutations in complement inhibitors, and/or presence of autoantibodies for complete penetrance of diseases such as aHUS $[39,40]$. The kidney is the organ that is especially vulnerable to complement-mediated damage, as on the one hand it filters substantial amount of blood under high pressure and on the other hand only a single layer, flat epithelium separates the glomerular structures from the bloodstream. It is known that $\mathrm{C} 3 \mathrm{NeF}$ may be a single factor sufficient to cause dense deposit disease or $\mathrm{C} 3$ glomerulonephritis. In contrast to uncontrolled amplification of the alternative pathway as a causative factor of autoinflammatory diseases, understanding a role for $\mathrm{C} 4 \mathrm{NeF}$ as a sole causative factor is more difficult. Certain hints may be obtained from the C4NeF cases reported in SLE [14], an autoimmune disease associated with occurrence of autoantibodies targeting DNA and nuclear antigens [41]. Importantly, the possible repertoire of targets for autoantibodies is much broader, including membrane proteins and extracellular matrix proteins [41, 42]. It is highly possible that a certain pool of autoantibodies exists in healthy individuals but their effector functions are blocked by anti-idiotypic antibodies [43, 44] or, alternatively, they are present at low titers, which are not relevant for massive complement activation. However, the appearance of $\mathrm{C} 4 \mathrm{NeF}$ may disturb this equilibrium and push complement activation to a pathological extent.

In the present work, we report a patient who presented with hypocomplementemia, but no risk factors other than $\mathrm{C} 4 \mathrm{NeF}$ could be identified in spite of detailed investigation. Since this is not the only reported case showing that $\mathrm{C} 4 \mathrm{NeF}$ may exist independently from other factors or autoantibodies causing dysfunction of the complement system $[13,15,16]$, our finding emphasizes the importance of screening for abnormal activity of classical convertases in clinical practice. The assay we propose is superior to other methods, as measurement of convertase activity in serum or diluted plasma takes into account all interactions, which may be physiologically relevant. Otherwise, putative masking effects of other plasma proteins or possible antagonisms or synergies taking place in individual samples may be lost and the obtained results may be over- or underestimated. Our results show that presence of $\mathrm{C} 4 \mathrm{NeF}$ may be the only pathogenic factor found in $\mathrm{C} 3 \mathrm{G}$ patients. Given that $\mathrm{C} 4 \mathrm{NeF}$ is a rare phenomenon, it would be useful to implement an algorithm for selection of patients, which should be further screened for factors affecting the activity of classical convertases. One would expect that $\mathrm{C} 4 \mathrm{NeF}$ should deplete available pool of $\mathrm{C} 3$ and $\mathrm{C} 5$, leave C4 level unaffected, and increase production of sC5b-9. On the other hand, autoantibodies targeting the alternative complement pathway as well as mutations in complement components would act as confounding factors for $\mathrm{C} 4 \mathrm{NeF}$. Figure 5 presents a scheme of deduction aimed to select patients with hyperactive classical convertases.

We attempted to make an insight into the nature of $\mathrm{C} 4 \mathrm{NeF}$ identified in patient seven and found that the Ig fraction was capable of preventing the classical convertases from either spontaneous or inhibitor-driven decay, as evidenced by usage of CD55 as a model complement inhibitor with decayaccelerating function [45]. Also, we showed that, similar to another reported case of $\mathrm{C} 4 \mathrm{NeF}$ [15], the stabilization effect was exerted for both $\mathrm{C} 3$ and $\mathrm{C} 5$ classical convertases, but in contrast to a report by Gigli et al. [12], we did not observe protection from proteolytic inactivation of $\mathrm{C} 4 \mathrm{~b}$. This speaks for heterogeneity of $\mathrm{C} 4 \mathrm{NeF}$ and suggests that these autoantibodies are not monospecific but target multiple epitopes on classical convertases, depending on the donor. Possible associations with diseases and/or severity are still to come once more cases of $\mathrm{C} 4 \mathrm{NeF}$ will be functionally characterized.

Acknowledgments We thank Dr. Ben King, Lund University, for the language revision of the manuscript. Michal Magda is a student of Biotechnology at the University of Rzeszow, Poland.

This study was supported by the National Science Centre Poland (2014/14/E/NZ6/00182), Swedish Research Council (K2012-66X14928-09-5), grants from the Spanish Ministerio de Economía y Competitividad (SAF2012-38636), Comunidad de Madrid (S2010/ BMD-2316) and CIBERER (ACCI-2014) and Foundations of Österlund, Greta and Johan Kock, King Gustav V's 80th Anniversary, Knut and Alice Wallenberg, Inga-Britt and Arne Lundberg, and grants for clinical research (ALF and from the Skåne University Hospital).

Authorship contributions M.O. and A.B. designed the study; M.O., F.C., G.S., M.M., and P.N. contributed to the experimental work; M.Á. PV., V.C-C., and M.L-T handled the selection, diagnosis, and clinical description of the patient. Genetic analyses were done by S.R.dC.; and writing of the manuscript was done by M.O. and A.B.

Compliance with Ethical Standards The experiments in this study were done after written informed consent had been obtained and according to the permits issued by the Hospital Universitario La Paz and by the ethics committee in Lund (permit number 2013/846).

Conflict of interest The authors declare that they have no conflict of interest.

Open Access This article is distributed under the terms of the Creative Commons Attribution 4.0 International License (http:// creativecommons.org/licenses/by/4.0/), which permits unrestricted use, distribution, and reproduction in any medium, provided you give appropriate credit to the original author(s) and the source, provide a link to the Creative Commons license, and indicate if changes were made. 


\section{References}

1. Merle NS, Church SE, Fremeaux-Bacchi V, Roumenina LT. Complement system part I-molecular mechanisms of activation and regulation. Front Immunol. 2015;6:262.

2. Ricklin D, Hajishengallis G, Yang K, Lambris JD. Complement: a key system for immune surveillance and homeostasis. Nat Immunol. 2010;11(9):785-97.

3. Okroj M, Holmquist E, King BC, Blom AM. Functional analyses of complement convertases using $\mathrm{C} 3$ and $\mathrm{C} 5$-depleted sera. PLoS One. 2012;7(10):e47245.

4. de Cordoba SR, Tortajada A, Harris CL, Morgan BP. Complement dysregulation and disease: from genes and proteins to diagnostics and drugs. Immunobiology. 2012;217(11):1034- 46.

5. Sethi S, Fervenza FC. Membranoproliferative glomerulonephritis - a new look at an old entity. N Engl J Med. 2012;366(12): 1119-31.

6. Nester CM, Barbour T, de Cordoba SR, Dragon-Durey MA, Fremeaux-Bacchi V, Goodship TH, et al. Atypical aHUS: state of the art. Mol Immunol. 2015;67(1):31-42.

7. Haffner K, Michelfelder S, Pohl M. Successful therapy of C3Nefpositive $\mathrm{C} 3$ glomerulopathy with plasma therapy and immunosuppression. Pediatr Nephrol. 2015;30(11):1951-9.

8. Gewurz AT, Imherr SM, Strauss S, Gewurz H, Mold C. C3 nephritic factor and hypocomplementaemia in a clinically healthy individual. Clin Exp Immunol. 1983;54(1):253-8.

9. Servais A, Noel LH, Roumenina LT, Le Quintrec M, Ngo S, Dragon-Durey MA, et al. Acquired and genetic complement abnormalities play a critical role in dense deposit disease and other $\mathrm{C} 3$ glomerulopathies. Kidney Int. 2012;82(4):454-64.

10. Jozsi M, Reuter S, Nozal P, Lopez-Trascasa M, Sanchez-Corral P, Prohaszka Z, et al. Autoantibodies to complement components in C3 glomerulopathy and atypical hemolytic uremic syndrome. Immunol Lett. 2014;160(2):163-71.

11. Halbwachs L, Leveille M, Lesavre P, Wattel S, Leibowitch J. Nephritic factor of the classical pathway of complement: immunoglobulin $\mathrm{G}$ autoantibody directed against the classical pathway $\mathrm{C} 3$ convetase enzyme. J Clin Invest. 1980;65(6):1249-56.

12. Gigli I, Sorvillo J, Mecarelli-Halbwachs L, Leibowitch J. Mechanism of action of the $\mathrm{C} 4$ nephritic factor. Deregulation of the classical pathway of C3 convertase. J Exp Med. 1981;154(1):112.

13. Ohi $\mathrm{H}$, Yasugi T. Occurrence of $\mathrm{C} 3$ nephritic factor and $\mathrm{C} 4$ nephritic factor in membranoproliferative glomerulonephritis (MPGN). Clin Exp Immunol. 1994;95(2):316-21.

14. Daha MR, van Es LA. Relative resistance of the F-42-stabilized classical pathway $\mathrm{C} 3$ convertase to inactivation by C4-binding protein. J Immunol. 1980;125(5):2051-4.

15. Miller EC, Chase NM, Densen P, Hintermeyer MK, Casper JT, Atkinson JP. Autoantibody stabilization of the classical pathway $\mathrm{C} 3$ convertase leading to $\mathrm{C} 3$ deficiency and Neisserial sepsis: C4 nephritic factor revisited. Clin Immunol. 2012;145(3):241-50.

16. Zhang Y, Nester CM, Smith RJ. C4 nephritic factor in C3 glomerulopathy. Mol Immunol. 2014;61(2):227.

17. Ito S, Tamura N, Fujita T. Effect of decay-accelerating factor on the assembly of the classical and alternative pathway $\mathrm{C} 3$ convertases in the presence of C4 or C3 nephritic factor. Immunology. 1989;68(4): 449-52.

18. Seino J, Kinoshita Y, Sudo K, Horigome I, Sato H, Narita M, et al. Quantitation of C4 nephritic factor by an enzyme-linked immunosorbent assay. J Immunol Methods. 1990;128(1):101-8.

19. Blom AM, Volokhina EB, Fransson V, Stromberg P, Berghard L, Viktorelius $\mathrm{M}$, et al. A novel method for direct measurement of complement convertases activity in human serum. Clin Exp Immunol. 2014;178:142-53.

20. Okroj M, Mark L, Stokowska A, Wong SW, Rose N, Blackbourn DJ, et al. Characterization of the complement inhibitory function of rhesus rhadinovirus complement control protein (RCP). J Biol Chem. 2009;284(1):505-14.

21. Dahlbäck B. Purification of human C4b-binding protein and formation of its complex with vitamin K-dependent protein S. Biochem J. 1983;209:847-56.

22. Blom AM, Kask L, Dahlbäck B. CCP1-4 of the C4b-binding protein a-chain are required for factor I mediated cleavage of C3b. Mol Immunol. 2003;39:547-56.

23. Hardig Y, Hillarp A, Dahlback B. The amino-terminal module of the C4b-binding protein alpha-chain is crucial for $\mathrm{C} 4 \mathrm{~b}$ binding and factor I-cofactor function. Biochem J. 1997;323(Pt 2): 469-75.

24. Delvaeye M, Noris M, De Vriese A, Esmon CT, Esmon NL, Ferrell $\mathrm{G}$, et al. Thrombomodulin mutations in atypical hemolytic-uremic syndrome. N Engl J Med. 2009;361(4):345-57.

25. Fremeaux-Bacchi V, Dragon-Durey MA, Blouin J, Vigneau C, Kuypers D, Boudailliez B, et al. Complement factor I: a susceptibility gene for atypical haemolytic uraemic syndrome. J Med Genet. 2004;41(6):e84.

26. Fremeaux-Bacchi V, Miller EC, Liszewski MK, Strain L, Blouin J, Brown $\mathrm{AL}$, et al. Mutations in complement $\mathrm{C} 3$ predispose to development of atypical hemolytic uremic syndrome. Blood. 2008;112(13):4948-52.

27. Corvillo F, Garcia-Morato MB, Nozal P, Garrido S, Tortajada A, de Cordoba SR, et al. Serum properdin consumption as a biomarker of C5 convertase dysregulation in $\mathrm{C} 3$ glomerulopathy. Clin Exp Immunol. 2015.

28. Delgado-Cervino E, Fontan G, Lopez-Trascasa M. C5 complement deficiency in a Spanish family. Molecular characterization of the double mutation responsible for the defect. Mol Immunol. 2005;42(1):105-11.

29. Paixao-Cavalcante D, Lopez-Trascasa M, Skattum L, Giclas PC, Goodship TH, de Cordoba SR, et al. Sensitive and specific assays for C3 nephritic factors clarify mechanisms underlying complement dysregulation. Kidney Int. 2012;82(10):1084-92.

30. Nozal P, Garrido S, Martinez-Ara J, Picazo ML, Yebenes L, Alvarez-Doforno R, et al. Case report: lupus nephritis with autoantibodies to complement alternative pathway proteins and $\mathrm{C} 3$ gene mutation. BMC Nephrol. 2015;16:40.

31. Abarrategui-Garrido C, Martinez-Barricarte R, Lopez-Trascasa M, de Cordoba SR, Sanchez-Corral P. Characterization of complement factor H-related (CFHR) proteins in plasma reveals novel genetic variations of CFHR1 associated with atypical hemolytic uremic syndrome. Blood. 2009;114(19):4261-71.

32. Blom AM, Osterborg A, Mollnes TE, Okroj M. Antibodies reactive to cleaved sites in complement proteins enable highly specific measurement of soluble markers of complement activation. Mol Immunol. 2015;66(2):164-70.

33. Okroj M, Hsu YF, Ajona D, Pio R, Blom AM. Non-small cell lung cancer cells produce a functional set of complement factor I and its soluble cofactors. Mol Immunol. 2008;45(1):169-79.

34. Härdig Y, Hillarp A, Dahlbäck B. The amino-terminal module of the $\mathrm{C} 4 \mathrm{~b}$-binding protein alpha-chain is crucial for $\mathrm{C} 4 \mathrm{~b}$ binding and factor I-cofactor function. Biochem J. 1997;323:469-75.

35. Ricklin D, Lambris JD. Therapeutic control of complement activation at the level of the central component C3. Immunobiology. 2015.

36. Blom AM, Kask L, Dahlbäck B. Structural requirements for the complement regulatory activities of C4BP. J Biol Chem. 2001;276(29):27136-44.

37. Goodship TH. Factor H, genotype-phenotype correlations: lessons from aHUS, MPGN II, and AMD. Kidney Int. 2006;70(1):12-3. 
38. Langford-Smith A, Day AJ, Bishop PN, Clark SJ. Complementing the sugar code: role of GAGs and sialic acid in complement regulation. Front Immunol. 2015;6:25.

39. Esparza-Gordillo J, Jorge EG, Garrido CA, Carreras L, LopezTrascasa M, Sanchez-Corral P, et al. Insights into hemolytic uremic syndrome: segregation of three independent predisposition factors in a large, multiple affected pedigree. Mol Immunol. 2006;43(11): $1769-75$.

40. Kavanagh D, Goodship TH. Atypical hemolytic uremic syndrome, genetic basis, and clinical manifestations. Hematol Am Soc Hematol Educ Program. 2011;2011:15-20.

41. Zhu H, Luo H, Yan M, Zuo X, Li QZ. Autoantigen microarray for high-throughput autoantibody profiling in systemic lupus erythematosus. Genomics Proteomics Bioinformatics. 2015;13(4):210-8.
42. Mastroianni-Kirsztajn G, Hornig N, Schlumberger W. Autoantibodies in renal diseases - clinical significance and recent developments in serological detection. Front Immunol. 2015;6:221.

43. Shoenfeld Y. The idiotypic network in autoimmunity: antibodies that bind antibodies that bind antibodies. Nat Med. 2004;10(1): $17-8$.

44. Seite JF, Shoenfeld Y, Youinou P, Hillion S. What is the contents of the magic draft IVIg? Autoimmun Rev. 2008;7(6):435-9.

45. Lukacik P, Roversi P, White J, Esser D, Smith GP, Billington J, et al. Complement regulation at the molecular level: the structure of decay-accelerating factor. Proc Natl Acad Sci U S A. 2004;101(5):1279-84. 